\title{
Genomic regions associated with resistance to peanut bud necrosis disease (PBND) in a recombinant inbred line (RIL) population
}

\author{
Yashoda Jadhav ${ }^{1,2}$ | Surendra S. Manohar ${ }^{1}$ | Gururaj Sunkad ${ }^{2}$ | Viswanatha P. Kannalli ${ }^{3}$ | \\ Manish K. Pandey ${ }^{1}$ | Murali T. Variath ${ }^{1}$ | Shasidhar Yaduru' ${ }^{1}$ | Praveen Kona ${ }^{4}$ | \\ Rajeev K. Varshney ${ }^{1}$ (D) | Janila Pasupuleti ${ }^{1}$ (D)
}

${ }^{1}$ International Crops Research Institute for the Semi-Arid Tropics (ICRISAT), Patancheru, Hyderabad, India

${ }^{2}$ University of Agricultural Sciences (UAS), Raichur, India

${ }^{3}$ Mahatma Phule Krishi Vidyapeeth (MPKV), Rahuri, India

${ }^{4}$ Directorate of Groundnut Research (DGR), Junagadh, India

\section{Correspondence}

Janila Pasupuleti, International Crops

Research Institute for the Semi-Arid Tropics (ICRISAT), Patancheru, Hyderabad 502324,

Telangana, India.

Email: p.janila@cgiar.org

Funding information

OPEC Fund for International Development; Bill and Melinda Gates Foundation (BMGF);

CRP-Grain Legumes and Dryland Cereals

Communicated by: Bradley Morris

\begin{abstract}
Parents and $318 \mathrm{~F}_{8}$ recombinant inbred lines (RILs) derived from the cross, TAG $24 \times$ ICGV 86031 were evaluated for peanut bud necrosis disease (PBND) resistance and agronomic traits under natural infestation of thrips at a disease hotspot location for 2 years. Significant genotype, environment and genotype $\times$ environment interaction effects suggested role of environment in development and spread of the disease. Quantitative trait loci (QTL) analysis using QTL Cartographer identified a total of 14 QTL for six traits of which five QTL were for disease incidence. One quantitative trait locus q60DI located on LG_Ahll was identified using both QTL Cartographer and QTL Network. Another QTL q90DI was detected with a high PVE of 12.57 using QTL Cartographer. $A$ total of nine significant additive $\times$ additive $(A A)$ interactions were detected for PBND disease incidence and yield traits with two and seven interactions displaying effects in favour of the parental and recombinant genotype combinations, respectively. This is the first attempt on QTL discovery associated with PBND resistance in peanut. Superior RILs identified in the study can be recycled or released as variety following further evaluations.
\end{abstract}

\section{KEYWORDS}

disease hotspot, peanut bud necrosis disease, Phenotypic Variance, quantitative trait loci, recombinant inbred line, simple sequence repeat

\section{1 | INTRODUCTION}

Peanut or groundnut (Arachis hypogaea L.) is an important oil, food and feed legume crop cultivated in over 100 countries on an area of 25.7 Mha with a total production of $42.4 \mathrm{Mt}$ (FAO, 2014). Peanut kernels are essentially rich in oil (48\%-50\%), carbohydrates (10\%$20 \%$ ) and protein (25\%-28\%). The kernels are also a good source of several essential bioactive compounds such as vitamins, minerals, antioxidants, polyphenols, flavonoids and isoflavones (Janila et al., 2013). Among the biotic stresses that constrain peanut production, peanut bud necrosis disease (PBND) caused by peanut bud necrosis virus, vectored by Thrips palmi, poses a serious threat to peanut production in South Asia (Satyanarayana et al., 1996), and in parts of China, Nepal, Sri Lanka and Thailand (Reddy et al., 1995). In India, PBND was first recorded in 1960s (Dwivedi, Nigam, Reddy, Reddy, \& Ranga Rao, 1995) and the predicted annual pod yield loss due to the disease stands at 89 million US dollars (Naidu et al., 1999). The disease occurs throughout the year, but the incidence of disease can vary depending on the time of infection, season, location and year (Buiel, Lenne, \& Jillian, 1995). In India, the PBND incidence 
varies from $5 \%$ to $80 \%$ across the major peanut-growing areas (Basu, 1995; Dwivedi et al., 1995). Pods do not develop in the plants infected by PBND, when the infection happens within 50 days after sowing (DAS), while those plants aged $>70$ DAS are less susceptible and show normal pod development (Gopal \& Upadhyaya, 1991). The seeds from infected plants often fail to germinate or produce vigorous plants after germination (Buiel, 1996; Singh, Gupta, \& Kaushik, 1997; Wongkaew, 1993).

Use of pesticides to control the insect vector is not effective due to the continuous migration of thrips into groundnut fields from the surrounding areas. Besides, it increases the input cost, thus not an economically viable option for resource-poor farmers in Africa and Asia. Breeding for host plant resistance is the most widely adopted and most effective component of disease management and is an environmentally sustainable option. In the case of PBND, breeding for resistance to the virus and to the vector or both can be considered to control the occurrence of virus disease to reduce economic losses. Developing a reliable screening protocol, identification of resistant sources, and knowledge on the genetics of the trait are critical for breeding peanuts with resistance to PBND, and further identification of genes/Quantitative trait loci (QTL) involved in governing the resistance trait will enable the deployment of markers for selection of target trait. Sources of resistance used in breeding for PBND-resistance are available in both cultivated peanut and wild Arachis species for use in breeding PBND-resistant lines (Dwivedi et al., 1995; Nigam, 2015). Hybridization using resistant cultivated sources followed by the screening of progenies in advance generation ( $F_{5}$ onwards) for PBND under field conditions and/or hotspot locations was employed for PBND resistance breeding. Field screening is often done on fixed lines and sometimes involves evaluation of selected lines for more than one season to avoid chance escapes.

Genetic studies concluded additive inheritance of resistance to PBND and absence of dominance and epistatic gene effects (Buiel, 1996; Kesmala, 2003). Involvement of dominance, additive $\times$ additive and additive $\times$ dominance besides additive gene effects was also reported by some studies (Pensuk, Daengpluang, Wongkaew, Jogloy, \& Patanothai, 2002; Pensuk, Jogloy, Wongkaew, \& Patanothai, 2004; Pensuk, Wongkaew, Jogloy, \& Patanothai, 2002; Poledate et al., 2007). Due to the presence of significant reciprocal effects (Pensuk et al., 2004), it was suggested to use resistance source as female parent in hybridization programme. Based on Generation Mean Analysis (GMA), Pensuk et al. (2004) reported multiple genes governing resistance to PBND, and the two resistant lines used in the study, ICGV 86388 and IC 10 differed in some of these genes.

Development and deployment of molecular markers enabled breeders to adopt modern crop breeding approaches like, marker-assisted selection (MAS) and marker-assisted backcrossing (MABC) to compliment the phenotypic selection. When reliable and cost-effective markers are developed, marker-assisted breeding (MAB) offers considerable advantages in terms of early generation selection and possible optimization of time and resources. MAB has been successfully deployed in peanut to introgress QTL governing resistance to foliar fungal diseases (rust and late leaf spot) into three popular cultivars belonging to early maturity group (Janila et al., 2015; Varshney et al., 2014) and also for transferring the high oleic trait to elite lines (Chu et al., 2011; Holbrook, Ozias-Akins, Chu, \& Guo, 2011; Janila et al., 2016). The identification of markers linked to the trait of interest is the base to develop markers for use in MAB. The first marker-trait associations study for PBND resistance reported a random amplified polymorphic DNA (RAPD) marker, OPG16850 linked to PBND resistance (Nipaporn, Pensuk, Jogloy, \& Sanitchon, 2008). Molecular diversity studies using different simple sequence repeat (SSR) markers have grouped a set of line into PBND resistant and susceptible clusters (Kamdar, Goswami, \& Bera, 2014; Srinivasaraghavan, Sunkad, Bera, \& Revadi, 2012). Three SSR markers PM15190, PM188165 and PM201130 were reported to differentiate the PBND-resistant lines from susceptible lines in a set of interspecific derivatives (Bera, Kamdar, Maurya, \& Dash, 2014). The recent availability of dense genetic maps (Ravi et al., 2011; Varshney et al., 2009) and genome sequence of diploid progenitors of peanut (Bertioli et al., 2016; Chen et al., 2016) offers the opportunity to identify major QTL linked to key target traits through marker-trait associations and develop diagnostic markers that can be deployed in peanut improvement programme. In the present study, a $F_{8}$ generation recombinant inbred line (RIL) population derived from the cross between PBND susceptible parent, TAG24 and resistant parent, ICGV 86031 following single seed descent method was phenotyped to identify QTL associated with PBND resistance in peanut. The study involved two seasons of screening of RIL population for PBND reaction and agronomic traits at a disease hot spot location, and identified potential PBND-resistant RILs with desirable morphological and agronomic features for variety release trials and/or for recycling as parents in breeding programmes.

\section{2 | MATERIALS AND METHODS}

\section{1 | Mapping population}

A RIL population comprising of $318 \mathrm{~F}_{8}$ lines derived from the cross, TAG $24 \times$ ICGV 86031 through single seed descent method was used in the study. TAG 24, susceptible to PBND is an improved Spanish Bunch variety developed by the Bhabha Atomic Research Center (BARC), Trombay, India from a cross, TGS-2 (TG-18A × M 13) × TGE-1 (Tall mutant $\times$ TG-9). Whereas, ICGV 86031, a derivative of F 334 A-B-14 $\times$ NC Ac2214 cross, is a Spanish type variety resistant to PBND vector (Thrips palmi Karny) (Dwivedi et al., 1993; Palmer, Reddy, Wightman, \& Ranga Rao, 1990; Tabassum, Bhat, \& Sudini, 2017; Vijaya Lakshmi et al., 1995) was developed at the International Crops Research Institute for the Semi-Arid Tropics (ICRISAT), Patancheru, India.

\subsection{Disease screening of mapping population}

The mapping population of $318 \mathrm{~F}_{8}$ RILs along with parents were evaluated for PBND reaction in the field during 2014 and 2015 rainy season at disease hotspot location in Raichur, Karnataka, India (Basu, 1995). The trial was planted in alpha lattice design $(20 \times 16 \mathrm{~L})$ due to the large number of entries involved in the trial and to control random 
variations arising from soil heterogeneity within blocks. The screening protocols were standardized with two replications and as the number of lines is large, the experiment was conducted with two replications. Late planting in rainy season favours increase in vector population, hence the trial was late planted in the first week of August in both seasons to get high disease pressure through increased vector population. Each RIL was sown in a single row of $5 \mathrm{~m}$ length with 30 and $10 \mathrm{~cm}$ spacing between rows and plants, respectively. Seed treatment was done before planting to protect the crop from soil borne pathogens. The parental genotypes, TAG 24 and ICGV 86031 of mapping populations were also sown after every 50 rows as susceptible and resistant controls. Disease epiphytotic was created for the disease using the 'infector row technique'. Spreader rows of a highly susceptible cultivar 'TMV-2' were sown after every five rows as well as in the border areas around the field to maintain effective inocula load. Observations were recorded on reaction to PBND and agronomic traits that included, days to $50 \%$ flowering; disease incidence at 30 days after sowing (DAS) (\%), 60 DAS (\%) and 90 DAS (\%); days to maturity; haulm yield per plot (g); pod yield per plot $(\mathrm{g})$; shelling per cent (\%); and 100 seed weight (g). The PBND infected plant count was recorded thrice at 30 days intervals starting from 30 DAS, at each screening the number of infected plants was counted (taking into account the dead and infected plants recorded at previous interval), and converted into percentage of disease incidence using the formula:

$$
\text { Disease incidence }=\frac{\text { No. } \text { of infected plants }}{\text { Total no. of plants }}
$$

Area under disease progress curve (AUDPC) was also calculated for the superior performing genotypes using the formula:

$$
\text { AUDPC }=\sum_{i=1}^{n}\left[Y_{i+1}+Y_{i}\right] / 2\left[T_{i+1}-T_{i}\right]
$$

where: $Y_{i+1}=$ disease incidence at the ith observation, $T_{i}=$ time (days) at the ith observation, $n=$ total number of observations (Shaner \& Finney, 1977).

Haulm yield per plot, pod yield per plot, shelling per cent and 100 seed weight were recorded after harvest.

\section{3 | Statistical analysis}

Analysis of variance (ANOVA) was performed for the traits in individual seasons to test the significance of differences between RILs. Combined analysis of variance was done using the data recorded from both seasons to assess the environmental (season) differences and contribution of genotype $\times$ environment interactions to PBND disease reaction and yield parameters. To assess and quantify genetic variability among the RILs, phenotypic and genotypic coefficient of variance (PCV and GCV), heritability in broad sense $\left(h_{\mathrm{bs}}^{2}\right)$ on an entry mean basis, genetic advance (GA) and genetic advance as per cent of mean (GAM) were estimated using the following equations:

$$
\operatorname{PCV}(\%)=\frac{\sqrt{\sigma_{\mathrm{P}}^{2}}}{\text { Mean }} \times 100
$$

$$
\begin{gathered}
\mathrm{GCV}(\%)=\frac{\sqrt{\sigma_{\mathrm{G}}^{2}}}{\text { Mean }} \times 100 \\
h_{\mathrm{bs}}^{2}(\%)=\frac{\sigma_{\mathrm{G}}^{2}}{\sigma_{\mathrm{G}}^{2}+\left(\frac{\sigma_{\mathrm{GE}}^{2}}{e}\right)+\left(\frac{\sigma_{e}^{2}}{r e}\right)} \\
\mathrm{GA}=\mathrm{K} \times\left(\frac{\sigma_{\mathrm{G}}^{2}}{\sigma_{\mathrm{P}}^{2}}\right) \times \sqrt{\sigma_{\mathrm{P}}^{2}} \\
\operatorname{GAM}(\%)=\frac{\mathrm{GA}}{\text { Mean }} \times 100
\end{gathered}
$$

where, $\sigma_{\mathrm{G}}^{2}-$ Genotypic variance, $\sigma_{\mathrm{P}}^{2}$ - Phenotypic variance, $\sigma_{\mathrm{GE}}^{2}-$ Genotype environment interaction variance, $\sigma_{e}^{2}$ - Residual variance, $e$ - number of environments, $r$ - number of replications per environment, $\mathrm{K}$ - selection differential, the value of which is 2.06 at $5 \%$ selection intensity.

Phenotypic data were analysed using Genstat 15th edition software (http://www.genstat.co.uk). Frequency distribution was performed by Kolmogorov-Smirnov and Shapiro-Wilk tests using SPSS 16th edition software.

The genotypic and phenotypic correlation coefficients were worked out to determine the degree of association for a group of characters (diseases and productivity traits). The pooled correlations were analysed by using META-R ver. 6.0 software.

\subsection{Quantitative trait loci (QTL) analysis}

In the present study, for the identification of candidate or putative QTL for PBND resistance, a comprehensive and refined genetic map developed by Varshney et al. (2009) containing 191 SSR loci based on a single mapping population from the cross TAG $24 \times$ ICGV 86031 segregating for PBND was used. Kosambi's mapping function was used to convert recombination fractions into map distances in centiMorgans (cM).

Quantitative trait loci analysis was done using QTL Cartographer and QTL Network. The composite interval mapping (CIM) approach (Zeng, 1994) was employed using WinQTL Cartographer, version 2.5 (Wang, Basten, \& Zeng, 2007). CIM was performed using the Model 6 after scanning the genetic map and estimating the likelihood of a QTL and its corresponding effects at every $1 \mathrm{cM}$, using significant marker cofactors to adjust the phenotypic effects associated with other positions in the genetic map. The number of marker cofactors for background control was set by forwardbackward stepwise regression. A window size of $10 \mathrm{cM}$ was used, and therefore cofactors within $10 \mathrm{cM}$ on either side of the QTL test site were not included in the QTL model. When separated by a minimum distance of $20 \mathrm{cM}$, two peaks on one chromosome were considered as two different QTL (Ungerer, Halldorsdottir, Modliszewski, Mackay, \& Purugganan, 2002). Otherwise, the highest peak was chosen to more closely approximate the position of the QTL. The software QTLNetwork ver. 2.0, based on a mixed 
TAB LE 1 Combined ANOVA of 318 RILs of TAG $24 \times$ ICGV 86031 for peanut bud necrosis disease resistance and other parameters evaluated at hotspot location, Raichur, Karnataka, India during rainy season 2014 and 2015

\begin{tabular}{lrrrrrrrrrr}
$\begin{array}{l}\text { Source of } \\
\text { variation }\end{array}$ & df & \multicolumn{1}{c}{ D50F } & 30DI & 60DI & 90DI & DM & HYP & PYP & SH & HSW \\
\hline Entries & 319 & $2.73^{*}$ & $41.55^{*}$ & $76.10^{*}$ & $135.80^{*}$ & $18.57^{*}$ & $68,160^{*}$ & $11,438.00^{*}$ & $40.28^{*}$ & $42.42^{*}$ \\
\hline Rep & 3 & 1.79 & 29.19 & 41.82 & $1,304.47$ & 2.86 & 22,847 & $23,635.00$ & 4.13 & 4.50 \\
\hline Season & 1 & $8,549.11^{*}$ & $350.97^{*}$ & $1,145.39^{*}$ & $3,046.48^{*}$ & $22,730.65^{*}$ & $1,635,355^{*}$ & $3,668,371.00^{*}$ & $91.59^{*}$ & $96.01^{*}$ \\
\hline Rep/Block & 76 & 3.63 & 31.19 & 57.23 & 84.05 & 24.32 & 85,426 & $4,939.00$ & 20.28 & 2.92 \\
\hline Entries X Seson & 319 & $1.88^{*}$ & 21.95 & $31.67^{*}$ & $45.08^{*}$ & $13.56^{*}$ & $50,115^{*}$ & $8,503.00^{*}$ & $30.43^{*}$ & 3.19 \\
\hline Residual & 561 & 1.10 & 20.81 & 27.75 & 39.11 & 2.80 & 12,743 & $1,015.00$ & 6.27 & 3.83 \\
\hline
\end{tabular}

Abbreviations: 30DI, Per cent disease incidence at 30 DAS; 60DI, Per cent disease incidence at 60 DAS; 90DI, Per cent disease incidence at 90 DAS; D50F, Days to 50\% flowering (days); df, degrees of freedom; DM, days to maturity (days); HSW, 100 seed weight (g); HYP, haulm yield per plot (g); PYP, pod yield per plot (g); Rep, replication; SH, shelling per cent (\%).

*Significant at $1 \%$.
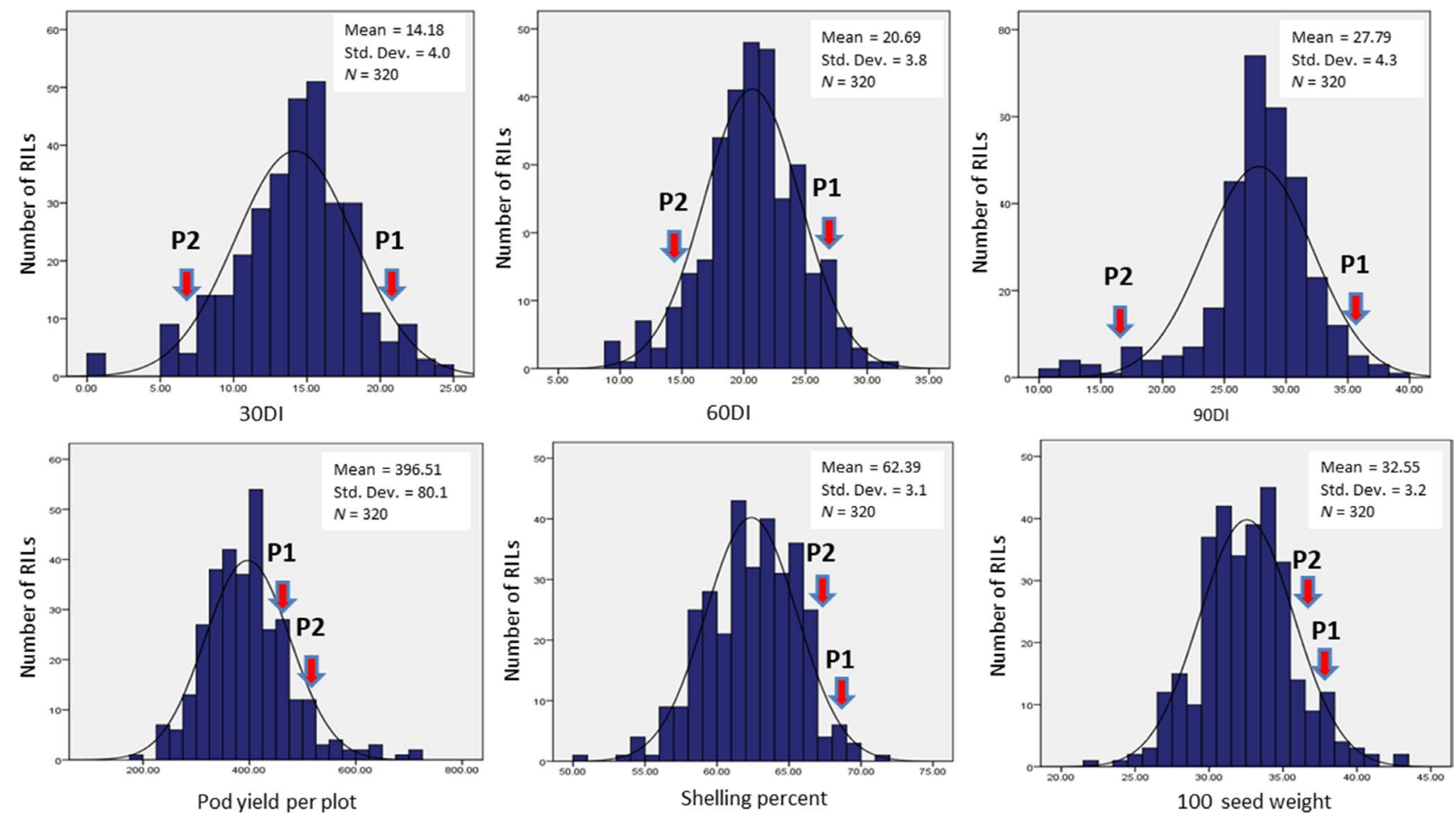

FIGURE 1 Frequency distribution of yield, yield components and disease incidence at different stages. The $X$-axis shows the percentage of the trait and the $Y$-axis represents the number of RILs. P1 and P2 represent the parents TAG 24 and ICGV 86031 respectively. $30 D I$, per cent of disease incidence at $30 \mathrm{DAS} ; 60 \mathrm{DI}$, per cent of disease incidence at $60 \mathrm{DAS}$; 90DI, per cent of disease incidence at 90 DAS

linear model was used to identify epistatic QTL (E-QTL) conditioning PBND parameters and yield related traits (Yang, Hu, Ye, \& Zhu, 2005). Mapchart 2.2 (Voorrips, 2002) was used to visualize the final marker positions of each linkage group (LG).

\section{3 | RESULTS}

\section{1 | Phenotypic variability and association}

The RIL population was phenotyped for PBND reaction and yield related traits for rainy season during 2014 and 2015 at disease hot spot of University of Agricultural Sciences, Raichur, India. Analysis of variance (ANOVA) for individual season (data not presented) revealed significant differences among RILs for all the traits under study. Combined ANOVA revealed significant genotype, environment and genotype $\times$ environment $(G \times E)$ interaction effects for all the traits of interest (Table 1).

The pooled frequency distribution for disease incidence (30DI, 60DI and 90DI), pod yield per plot, shelling per cent and 100 seed weight are shown in Figure 1. The parents TAG 21 (P1) and ICGV 86031 (P2) showed significant variation for disease incidence at 30, 60 and 90 DAS and days to maturity with P2 exhibiting low disease 
TA B LE 2 Variability among 318 RILs of TAG $24 \times$ ICGV 86031 based on individual and pooled data from 2014 and 2015 rainy season evaluation conducted at University of Agricultural Sciences, Raichur, Karnataka, India

\begin{tabular}{|c|c|c|c|c|c|c|c|c|c|c|}
\hline \multirow[b]{2}{*}{ Trait } & \multirow[b]{2}{*}{ Mean } & \multirow[b]{2}{*}{ Range } & \multicolumn{3}{|c|}{ GCV (\%) } & \multicolumn{3}{|c|}{ PCV (\%) } & \multirow[b]{2}{*}{$h_{b s}^{2}(\%)$} & \multirow[b]{2}{*}{ GAM (\%) } \\
\hline & & & 2014 & 2015 & Pooled & 2014 & 2015 & Pooled & & \\
\hline 30DI & 13.0 & $0-40.2$ & 82.6 & 62.3 & 87.2 & 111.7 & 88.7 & 112.6 & 60.0 & 139.1 \\
\hline 60DI & 20.3 & $0-45.0$ & 59.1 & 39.5 & 61.6 & 72.2 & 56.2 & 74.1 & 69.2 & 105.6 \\
\hline PYP & 249.8 & $85.0-621.0$ & 45.2 & 36.3 & 41.8 & 46.1 & 38.8 & 43.7 & 91.5 & 82.4 \\
\hline $\mathrm{SH}$ & 62.4 & $41.0-76.0$ & 10.0 & 8.7 & 9.8 & 10.5 & 9.8 & 10.6 & 85.6 & 18.6 \\
\hline HSW & 32.6 & $20.0-49.0$ & 16.0 & 11.7 & 19.6 & 17.3 & 12.9 & 20.5 & 91.4 & 38.5 \\
\hline HYP & 489.0 & $110.0-1,800.0$ & 62.8 & 39.9 & 52.1 & 64.5 & 48.5 & 57.0 & 83.6 & 273.7 \\
\hline
\end{tabular}

Abbreviations: 30DI, Per cent disease incidence at 30 DAS; 60DI, Per cent disease incidence at 60 DAS; 90DI, Per cent disease incidence at 90 DAS; D50F, Days to 50\% flowering (days); DM, Days to maturity (days); GAM, Genetic advance as per cent of mean; GCV, Genotypic coefficient of variation; $h_{\mathrm{bs}}^{2}$, Broad sense heritability; HSW, 100 seed weight (g); HYP, Haulm yield per plot (g); PCV, Phenotypic coefficient of variation; PYP, Pod yield per plot (g); $\mathrm{SH}$, Shelling per cent (\%).

incidence at all recorded dates, while most of the RILs were distributed between the parents. A few RILs with mean values lower than P2 were observed which indicates potential lines for PBND resistance. For pod yield per plot, the parent $\mathrm{P} 2$ had higher values than P1, while for shelling per cent and 100 seed weight, P1 had higher values than P2 but the difference was not very significant. However, the RIL population showed a complete distribution with values ranging from 110 to $1,800 \mathrm{~g} /$ plot for haulm yield, 85 to $621 \mathrm{~g} /$ plot for pod yield, $41 \%$ to $76 \%$ for shelling per cent and 20 to $49 \mathrm{~g}$ for 100 - seed weight indicating the presence of transgressive segregants for these traits.

The outcome of ANOVA was used for the calculation of phenotypic and genotypic coefficients of variation (GCV and PCV), heritability and to predict genetic advance as per cent of mean (GAM) for traits studied and is presented in Table 2. The population of RILs and its parents exhibited moderate to high variability for majority of the traits. The variation among the RILs for days to 50\% flowering is from 23 to 35 days. For other traits, the observed pooled variation over the two seasons is high; $0 \%-40 \%$ for per cent disease incidence at 30 DAS, 0\%-45\% for per cent disease incidence at 60 DAS, 0\%-57\% for per cent disease incidence at 90 DAS, 98-126 days for days to maturity, $85-621 \mathrm{~g} /$ plot for pod yield per plot, $41 \%-76 \%$ for shelling percentage, 110-1,800 g for haulm yield per plot and 20-49 g for 100 seed weight. High PCV and GCV were found for pod yield per plot, haulm yield per plot, per cent of disease incidence at 30, 60 and 90 DAS in individual and pooled across the seasons. However, days to $50 \%$ flowering, days to maturity, 100 seed weight and shelling per cent recorded low to moderate GCV and PCV. The traits viz., disease incidence at 30 DAS $(59.95 ; 139.07)$, disease incidence at 60 DAS (69.16; 105.57), disease incidence at 90 DAS (74.83; $86.93)$, pod yield per plot $(91.50 ; 82.40)$ and haulm yield per plot (83.60; 273.70) recorded high heritability coupled with high GAM; shelling per cent $(85.56 ; 18.61)$ and 100 seed weight $(91.36 ; 38.48)$ had high heritability with moderate GAM; while days to $50 \%$ flowering $(66.55 ; 8.86)$ and days to maturity $(86.00 ; 7.16)$ recorded high heritability but low GAM in pooled across the seasons (Table 2).

The pooled correlation between PBND parameters and yield attributes was estimated and the significant correlations (genotypic correlation values $>.5$ ) are shown in Table 3 . Significant positive association was found between per cent of disease incidence at 30 DAS with per cent of disease incidence at $60 \mathrm{DAS}\left(r_{\mathrm{G}}=.857 ; r_{\mathrm{P}}=.717\right)$ and $90 \mathrm{DAS}\left(r_{\mathrm{G}}=.762 ; r_{\mathrm{P}}=.644\right)$ and also between per cent of disease incidence at 60 DAS with per cent of disease incidence at 90 DAS $\left(r_{\mathrm{G}}=.949 ; r_{\mathrm{P}}=.891\right)$. Haulm yield showed negative significant correlation with per cent disease incidence at $30 \mathrm{DAS}\left(r_{\mathrm{G}}=-.986\right.$; $\left.r_{\mathrm{P}}=-.383\right), 60 \mathrm{DAS}\left(r_{\mathrm{G}}=-1.000 ; r_{\mathrm{P}}=-.524\right)$ and $90 \mathrm{DAS}\left(r_{\mathrm{G}}=-1.000\right.$; $\left.r_{P}=-.627\right)$. For the pairwise association between the other studied traits, the correlations were either very low or non-significant.

Superior performing RILs were identified based on disease incidence during 2014 and 2015 rainy season and mean pod yield performance. The BND score of the selected RILs varied from 0.0 (for BND-219 and BND-56 during 2014 and 2015, respectively) at 30 DAS to 9.6 for BND-104 at 90 DAS. The BND score of the resistant check (R-2001-2) and resistant parent (ICGV 86031) varied from 0.3 at 30 DAS to 8.7 at 90 DAS which were comparable to those of the selected RILs. The AUDPC values of the selected RILs were comparable to those of R-2001-2 and ICGV 86031 . The pod yield performance of the selected RILs ranged from $2 \%$ for BND-175 to $90 \%$ for BND-41 in comparison to R-2001-2.

\section{2 | Identification of QTL for resistance to PBND and yield traits}

Data obtained for resistance to PBND and yield related traits from both the seasons (2014 and 2015) were subjected to QTL analysis along with genotypic data. In the present study, a total of five QTL 
TABLE 3 Important phenotypic and genotypic correlation coefficient for PBND parameters and haulm yield per plot in an RIL population of groundnut

\begin{tabular}{|lll}
\hline SI No & Association between traits & Correlation coefficient \\
\hline 1. & $60 \mathrm{DI}$ and 30DI & $r_{\mathrm{P}}=.717^{*} ; r_{\mathrm{G}}=.857^{*}$ \\
\hline 2. & $90 \mathrm{DI}$ and 30DI & $r_{\mathrm{P}}=.644^{*} ; r_{\mathrm{G}}=.762^{*}$ \\
\hline 3. & $90 \mathrm{DI}$ and 60DI & $r_{\mathrm{P}}=.891^{*} ; r_{\mathrm{G}}=.949^{*}$ \\
\hline 4. & $\mathrm{HYP}$ and 30DI & $r_{\mathrm{P}}=-.383^{*} ; r_{\mathrm{G}}=-.986^{*}$ \\
\hline 5. & $\mathrm{HYP}$ and 60DI & $r_{\mathrm{P}}=-.524^{*} ; r_{\mathrm{G}}=-1.000^{*}$ \\
\hline 6. & HYP and 90DI & $r_{\mathrm{P}}=-.627^{*} ; r_{\mathrm{G}}=-1.000^{*}$ \\
\hline
\end{tabular}

Abbreviations: 30DI, Per cent disease incidence at 30 DAS; 60DI, Per cent disease incidence at $60 \mathrm{DAS} ; 90 \mathrm{DI}$, Per cent disease incidence at 90 DAS; HYP, Haulm yield per plot (g); $r_{G}$, Genotypic correlation; $r_{p}$, Phenotypic correlation.

${ }^{*}$ Significant at $1 \%$ probability.

were identified in two seasons for the per cent of PBND incidence at different screening intervals. Two QTL, that is, q30DI_2014 (LOD 2.84) and q30DI_2014 (LOD 2.80) with 3.92\% and 5.51\% of the total phenotypic variation explained (PVE), respectively, were located on LG_AhIX during rainy season 2014. Two other QTL viz., q30DI_2015 (LOD 2.89) and q90DI_2015 (LOD 3.06) were located on LG_AhVIII with $4.02 \%$ and $12.57 \%$ of PVE, respectively, during rainy season 2015. A single QTL, q60DI_2014 (LOD 3.00), with PVE of $4.79 \%$ located on LG_Ahll was identified for per cent disease incidence at 60 DAS during rainy season 2014 (Table 4 and Figure 2). For the QTL, q30DI_2015 and q60DI_2014 detected in rainy season 2015 and 2014, respectively, allele from TAG 24 contributed positively to improve PBND resistance in the RIL population. Among the QTL, q90DI_2015 (LOD 3.06) located on LG_AhVIII was identified with high PVE of $12.57 \%$ with the flanking markers Seq3A06 and IPAHM177 which can be deployed in marker-assisted breeding $(M A B)$ after further validation. The negative additive effect indicates that the allele contribution for resistance to PBND came from ICGV 86,031.

Apart from PBND resistance, QTL for agronomic and yield traits in respective environment under PBND disease pressure were also identified. Two QTL (qPYP_2014) were identified for the pod yield per plot during 2014 season located on LG_AhV and LG_AhXV with PVE of $4.79 \%$ and $5.92 \%$. One quantitative trait locus (qHYP_2015) located on LG_AhVIII with PVE of $4.24 \%$ was found for haulm yield per plot during rainy season 2015. One quantitative trait locus (qHSW_2014) located on LG_AhXVII during rainy season 2014 and other QTL (qHSW_2015) located on LG_AhXIII during rainy season 2015 were reported with PVE of $8.24 \%$ and $11.18 \%$, respectively, for 100 seed weight. Besides, a QTL (qD50F_2015) was identified contributing to days to $50 \%$ flowering located on LG_AhXVIII with the PVE of 4.91\% during rainy season 2015. Three QTL were identified for days to maturity where, two QTL (qDM_2014) were located on LG_AhXII and LG_AhXVI with PVE of $4.78 \%$ and $4.54 \%$, respectively, during rainy season 2014 and one quantitative trait locus (qDM_2015) located on LG_AhVI with PVE of 5.57\% during rainy season 2015. The additive effects for the QTL qPYP_2014, qDM_2014 and qDM_2015 came from TAG 24.

In order to compare the M-QTL identified by QTL Cartographer, QTL analysis was also carried out by another program, QTL Network. As a result, three QTL were identified. One quantitative trait locus (q60DI) for PBND at 60 DAS located on LG_Ahll having flanking markers PM499 and SEQ18E07 with a significant additive effect was also identified by QTL Cartographer on same linkage group. Two

TAB LE 4 Putative QTL identified for peanut bud necrosis disease, agronomic and yield traits in a RIL population (318) of TAG $24 \times$ ICGV 86031 evaluated during rainy season 2014 and 2015 at UAS Raichur, Karnataka, India

\begin{tabular}{|c|c|c|c|c|c|c|c|c|}
\hline Trait & QTL Name & Environment & Linkage groups & Position (cM) & Flanking markers & LOD & Additive $^{a}$ & $R^{2}$ \\
\hline 30DI & qD30DI_2014 & 2014 & IX & 44.51 & PM436-Lec1 & 2.84 & -1.10 & 3.92 \\
\hline 30DI & qD30DI_2015 & 2015 & VIII & 150.11 & IPAHM406-TC9F10 & 2.89 & 0.66 & 4.02 \\
\hline 60DI & qD60DI_2014 & 2014 & II & 95.11 & Seq18E07-RI1F06 & 3.00 & 1.43 & 4.79 \\
\hline HYP & qHYP_2015 & 2015 & VIII & 141.31 & GM679-IPAHM406 & 3.07 & -50.91 & 4.24 \\
\hline PYP & qPYP_2014 & 2014 & V & 6.91 & GM630-Seq10D04 & 3.29 & -14.13 & 4.79 \\
\hline PYP & qPYP_2014 & 2014 & $x V$ & 29.31 & GM2603-Seq16G08 & 3.13 & 15.50 & 5.92 \\
\hline HSW & qHSW_2014 & 2014 & $X V I I$ & 54.31 & IPAHM 108-S11 & 3.33 & -1.14 & 8.24 \\
\hline DM & qDM_2015 & 2015 & $\mathrm{VI}$ & 80.11 & TC1A02-GM623 & 3.92 & 0.40 & 5.57 \\
\hline
\end{tabular}

Abbreviations: 30DI, Per cent disease incidence at 30 DAS; 60DI, per cent disease incidence at 60 DAS; 90DI, per cent disease incidence at 90 DAS; D50F, days to 50\% flowering (days); DM, days to maturity (days); HSW, 100 seed weight (g); HYP, haulm yield per plot (g); LOD, logarithm of odds; PYP, pod yield per plot (g); $R^{2}$, Phenotypic variance explained.

${ }^{a} A$ positive sign indicates that the additive effects came from TAG 24 , and negative sign from ICGV 86031. 

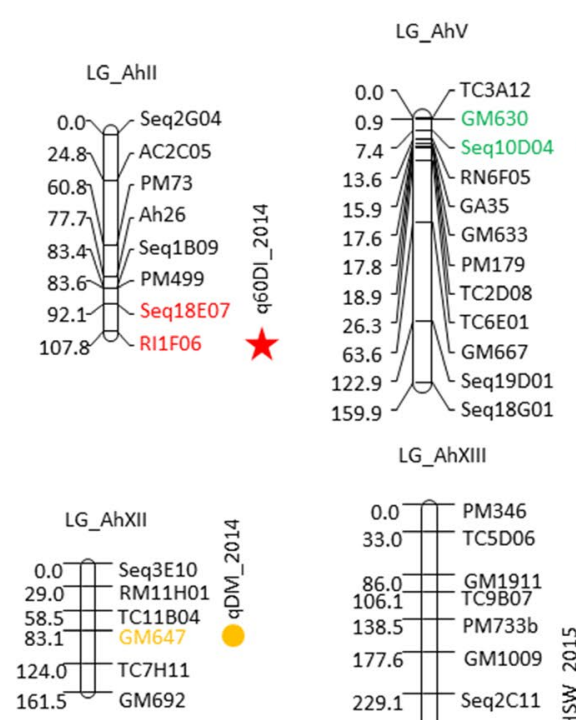

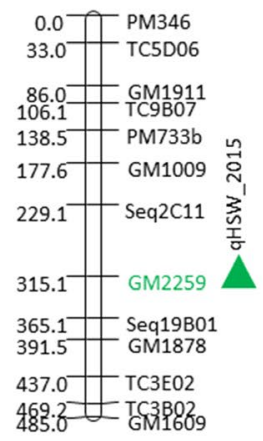

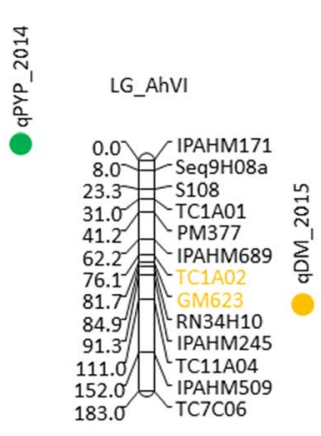
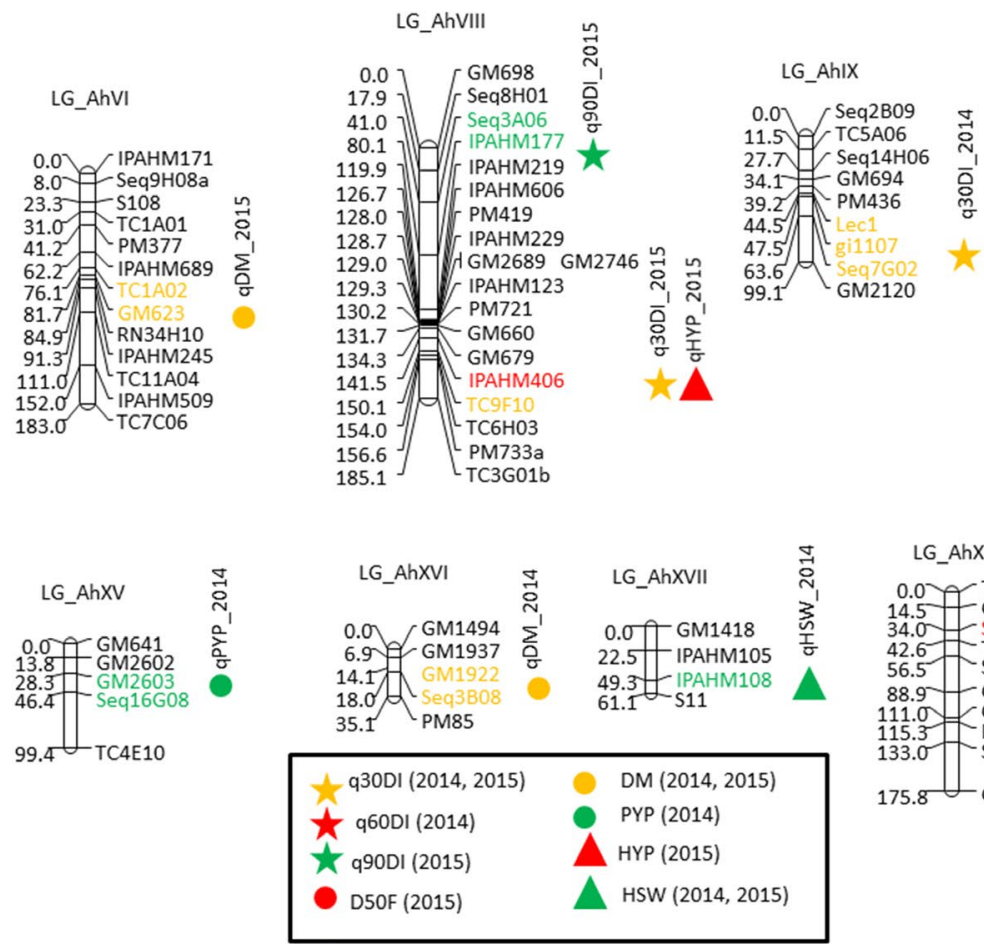

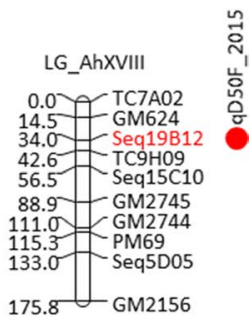

FIG URE 2 QTL location for PBND and yield parameters identified in the TAG $24 \times$ ICGV 86031 RIL population. QTL were represented by different geometrical figures and colour codes including star with yellow, red and green for 30DI, 60DI and 90DI (per cent disease incidence at 30, 60 and 90 DAS) respectively; circle with red, yellow and green for D50F (days to 50\% flowering), DM (days to maturity), PYP (pod yield per plot), respectively; and triangle with red and green for HYP (haulm yield per plot) and HSW (100 seed weight), respectively

QTL were identified for days to maturity (qDM) located on LG_AhXII and LG_AhXVI flanked by GM647-TC7H11 and GM1922-Seq3B08 markers, respectively.

\subsection{Significant additive and additive epistatic effects detected for PBND and yield traits}

A total of three M-QTL, one quantitative trait locus for 60DI and two QTL for DM were detected as having significant additive effects using QTL Network (Table 5) while no AE interactions were observed for the two seasons. For the epistatic effects, nine significant additive $\times$ additive (AA) interactions were detected for PBND disease incidence and yield traits and these are depicted in Table 5. Out of nine interactions, two and seven displayed effects in favour of the parental and recombinant genotype combinations, respectively. No additive $\times$ additive $\times$ environment (AAE) interaction was detected.

For days to $50 \%$ flowering, three QTL were involved in two significant $A A$ interactions with both interactions acting to increase the value of the recombinant type. Similarly, for the traits 90DI, shelling per cent and 100 seed weight significant AA interactions were observed among two QTL with all interactions acting in favour of the recombinant type. Four QTL were involved in three significant $A A$ interactions for days to maturity with qDM LGI and qDM LG VI acting to increase the values of the parental types, and the other two acting in the opposite direction. Similarly, for the trait 60DI, the QTL q60DI acted to increase the value of the parental type.

\section{4 | DISCUSSION}

Quantitative trait loci mapping is an important tool to identify molecular markers associated with disease resistance and for the deployment of MAB approaches in crop breeding programmes. Until recently, the low genetic diversity and the allotetraploid nature of cultivated peanut were considered a serious bottleneck in developing molecular tools for breeding. The development of the first SSRbased genetic map of peanut on RIL population derived from the cross TAG 24 × ICGV 86031 (Varshney et al., 2009) and its subsequent saturation with more number of SSR markers (Ravi et al., 2011) have enabled its utilization in breeding. Following this, several other genetic maps for cultivated peanut were developed by different researchers (Qin et al., 2012; Zhou et al., 2014).

Peanut bud necrosis disease is an important virus disease of peanut in South Asia and sources of resistance for vector are reported in cultivated germplasm. Breeding for PBND resistance requires screening of advanced generations in a hotspot location and quite often the screening has to be repeated to ascertain the level of resistance in selected progenies and avoid chance escapes. Pensuk, Jogloy, and Patanothai (2010) reported that low temperature or relative humidity did not have any effect on the transmissibility of PBNV under mechanical inoculation. It was asserted that the observed differences in disease incidence in the rainy and dry seasons can be attributed to the vector infestation. Cultural management practices such as adjustment of the planting 


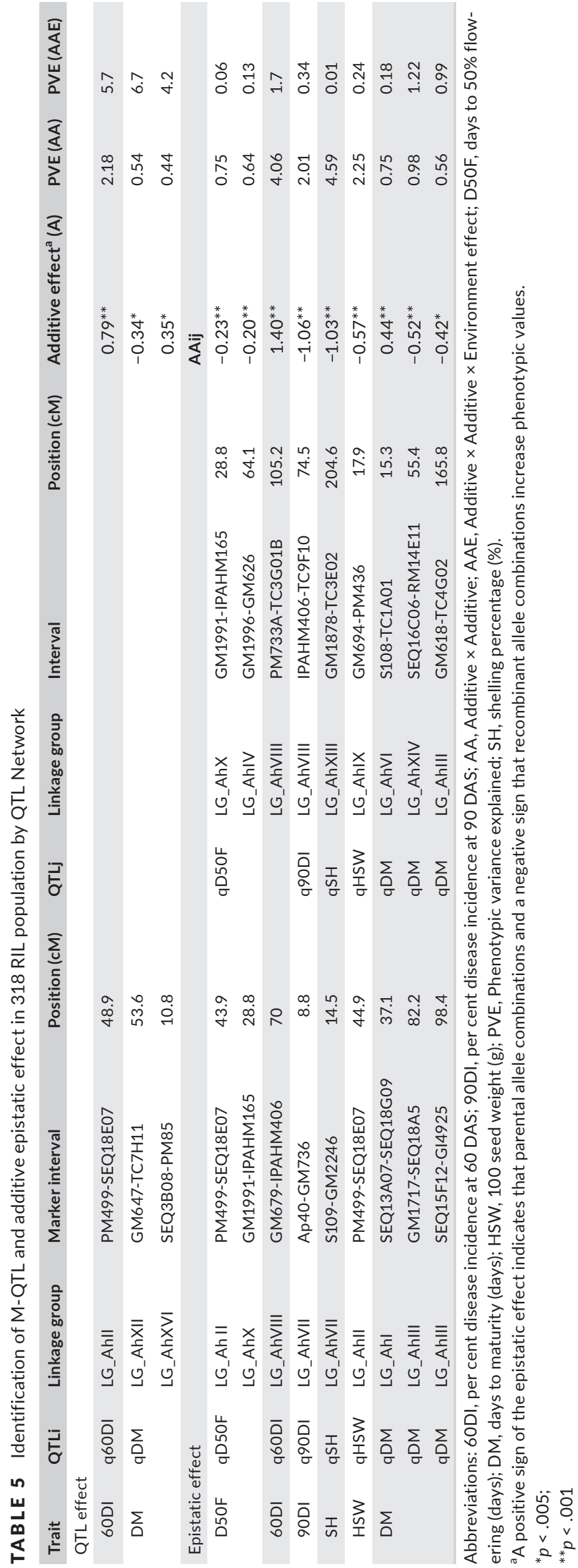

date to the period with low levels of vector activity, intercropping with fast growing cereals (Reddy et al., 2000), close spacing (Basu, 1995; Buiel, 1996) and irrigation (Bhatnagar, Reddy, Rao, \& Singh, 1995) can reduce disease incidence. In the present study, the experiment was conducted under field conditions during 2014 and 2015 rainy season and conditions such as temperature, rainfall and relative humidity could influence the spread of the vector. Also, no major genes for PBND resistance have been reported and the resistance being quantitative (Buiel, 1996; Pensuk, Wongkaew, et al., 2002; Poledate et al., 2007), there is a possibility of involvement of several minor genes, and the effect of many controlled by the environment.

Markers, if available, enable early generation selection of plants thus reducing the number of progenies for phenotyping and can thus optimize resources by way of rejecting plants in early generation based on markers. To develop such markers for use in breeding programme, a mapping population was developed at ICRISAT using a susceptible popular parent, TAG 24 and a PBND-resistant parent, ICGV 86031 following the single seed descent method. A $F_{8}$ generation RIL population derived from this cross was used in the study. The population was genotyped and phenotyped to identify QTL associated with resistance to PBND and with agronomic traits under PBND disease pressure, and understand their interactions in governing PBND resistance.

Reliable and multi-season phenotypic evaluation is critical to improve QTL mapping accuracy by reducing background noise and to identify reliable candidate QTL for MAB. The genetic estimates showed significant variation among the RILs for resistance to PBND and the magnitude of variation was moderate to high as revealed by the PCV and GCV. Moderate to high broad-sense heritability estimates of PBND incidence and PBND severity at 50 and 60 DAS were reported by Tonsomors et al. (2006) in $\mathrm{F}_{4}$ generation population. However Puttha et al. (2008) found that heritability for disease incidence and disease severity was cross-dependent and varied from low to relatively high. Significant variability was observed among the RIL population and based on disease score and pod yield some superior performing RILs were identified (Table 6) which can be recycled as parents in the breeding programme to enhance the rate of genetic gain for PBND resistance and/or can be directly advanced to variety release and adaptability trials. Moderate to high heritability estimates in the broad sense and genetic advance as per cent of the mean (GAM) observed in the study suggest possibility of improving resistance to PBND following selection in early segregating generations under disease pressure. Thus, in a breeding scheme for breeding peanut varieties with PBND resistance, early generation selection for PBND resistance under disease pressure followed by selection for yield traits with low heritability in later generations is desirable.

The frequency distribution (Figure 1) for disease incidence, and yield parameters showed normal to near normal distribution. For disease incidence score, a few transgressive segregants having lower score than the resistant parent ICGV 86031 were observed. Similar segregants were also observed for other traits. RILs having 
low disease incidence along with high pod yield, haulm yield, shelling per cent and hundred seed weight could be potential source for future breeding programmes. The quantitative nature with an additive effect on PBND resistance has been reported earlier (Buiel, 1996; Pensuk, Wongkaew, et al., 2002; Poledate et al., 2007). High PCV and GCV were found for pod yield, haulm yield, per cent of disease incidence at 30,60 and 90 DAS, in pooled season, signifying greater scope for the selection of superior RILs for disease incidence at different growth stages of crop. However, for days to $50 \%$ flowering, days to maturity, 100 seed weight and shelling per cent recorded low to moderate GCV and PCV. In earlier studies, high GCV and PCV were reported by Khote, Patil, Patil, and Walke (2009), Nath and Alam (2002), Parameshwarappa, Shobha Krupa Rani, and Bentur (2005), Patil, Shivanna, Irappa, and Shweta (2015) and Vishnuvardhan, Vasanthi and Hariprasad Reddy (2012) for pod and kernel yield; however low to moderate GCV and PCV was reported by Vishnuvardhan et al.(2012) for days to maturity, Vekariya et al. (2011) and ZamanTuhina-Khatun, Ullah, Moniruzzamn, and Alam (2011) for 100 seed weight and Khote et al. (2009) for haulm weight.

Disease resistance (PBND) and yield are complex traits resulting from the combined effect of several component characters, environment and their interactions (Nigam, 2015). Understanding of the association between characters and with the environment is of great use in peanut breeding as it enables selection for multiple traits in a breeding programme. Correlation studies can provide information on the nature and magnitude of association between any two trait pairs. Grafius (1959) opined that there may not be any gene for yield as such, but operate only through its components. Therefore knowledge about character association will help to identify the character to make a selection for disease resistance with higher yield. Correlation analysis revealed that the genotypic correlations were higher than their respective phenotypic correlation for most of the characters indicating that strong intrinsic associations are reduced at phenotypic level due to the environment and genotype $\times$ environment interaction components. Higher values of genotypic correlation than the phenotypic correlation coefficient between the pair of characters have been reported in soybean by Johanson, Robinson, and Comstock (1955).

Significant and positive association was found among the three disease parameters, per cent of disease incidence at 30, 60 and 90 DAS, suggesting that infected plant count recorded at one or two stages of plant growth will be sufficient to make selection decisions in breeding programmes for PBND resistance. Such a selection scheme is expected to optimize resources. Depending upon resource availability, disease incidence may be recorded at 60 DAS or at 60 and 90 DAS to identify resistant lines and use them in breeding. Kesmala et al. (2004) also reported significant positive correlations for PBND score with PBND incidence and Area Under Disease Progress Curve (AUDPC), and also PBND incidence and AUDPC with values of $0.91,0.87$ and 0.84 , respectively. In another study, Tonsomors et al. (2006) reported good agreement of genotypic and phenotypic correlations between disease incidence and disease severity scores for PBND in peanut. Haulm yield per plot was found to be significantly negatively associated with per cent disease incidence at 30, 60 and 90 DAS. The negative association between PBND and haulm yield per plot may be due to the reduced growth of the plant and death of the terminal buds upon infection by the virus. Significant negative association was detected for pod yield per plot with per cent disease incidence at 30,60 and 90 DAS and positive association with haulm yield per plot and 100 seed weight. Also, 100 seed weight had significant positive association with shelling percentage. However, the correlations were of low magnitude $(r=<.5)$ indicating low efficiency of simultaneous selection for these traits in the present study. Similarly, Kesmala et al. (2004) reported

TAB LE 6 Peanut bud necrosis resistant RILs identified based on disease incidence in evaluation trials conducted during 2014 and 2015 rainy season at University of Agricultural Sciences, Raichur, Karnataka, India

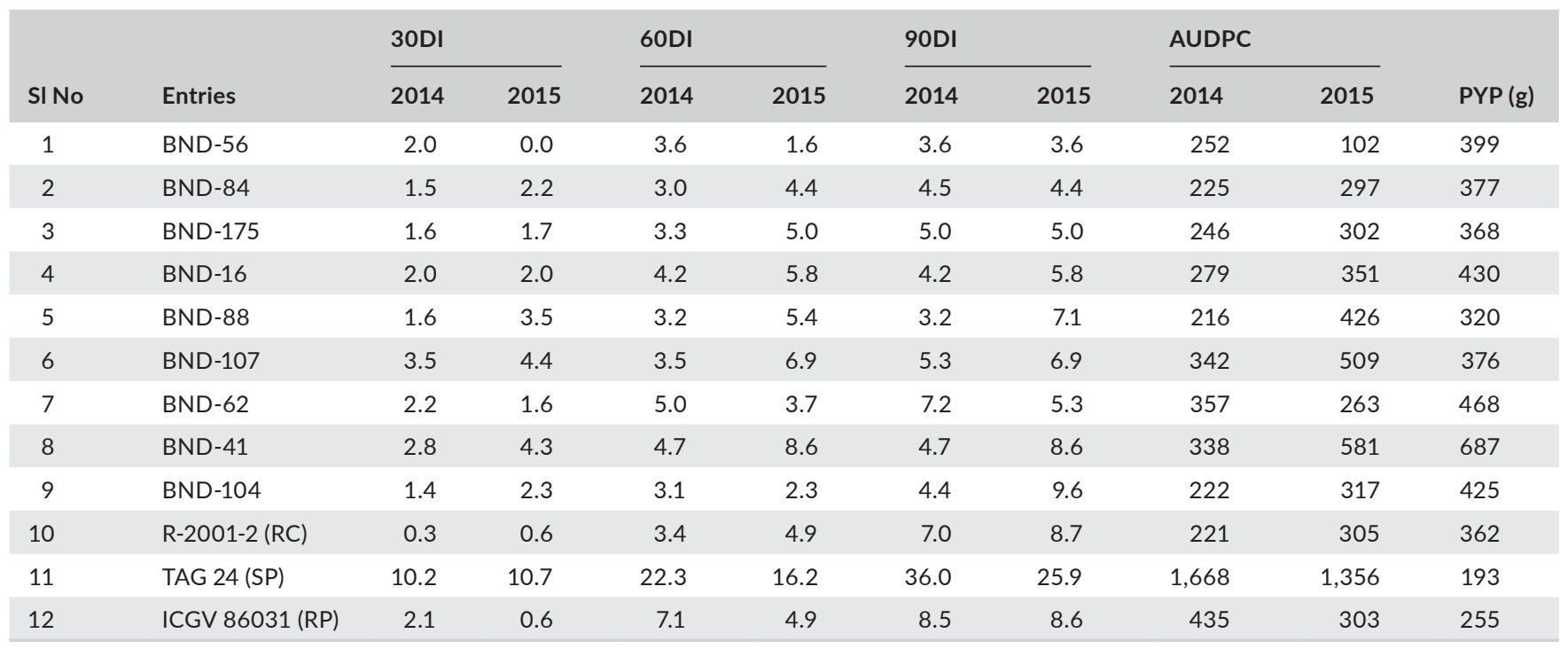

Abbreviations: 30DI, per cent disease incidence at $30 \mathrm{DAS}$; 60DI, per cent disease incidence at $60 \mathrm{DAS}$; 90DI, per cent disease incidence at $90 \mathrm{DAS}$; PYP, pod yield per plot; RC, resistant check; RP, resistant parent; SP, susceptible parent. 
low correlation for PBNV resistance with pod weight per plant, seed weight per plant, pod number per plant, seed number per plant, 100 seed weight and shelling percentage. However, Puttha et al. (2008) observed significant positive correlations between disease parameters and pod weight, 100 seed weight and harvest index. Buiel (1996) reported primary spread of PBND is more important than secondary spread and infected plants at early growth stages usually die and yield no pod. Therefore, selection should be done for lower disease incidence with good yield at later stages.

Earlier, attempts were made to study the molecular diversity and association of simple sequence repeat markers for PBND resistance in interspecific breeding lines and cultivars of peanut using Bulk Segregant Analysis (BSA) by Bera et al. (2014). They identified nine putative markers with regression coefficient value $\left(r^{2}\right)$ ranging from $10.1 \%$ to $77.5 \%$ for PBND resistance. Of these nine markers, PM15190, PM188165 and PM201130 could efficiently differentiate most of the resistant and susceptible lines. In another study, Kamdar et al. (2014) reported polymorphic information content (PIC) values ranging from 0.5 to 0.94 with the average of 0.82 in the molecular diversity analysis of 115 peanut interspecific lines using SSR markers. Similarly, Srinivasaraghavan et al. (2012) using SSR marker first reported molecular diversity in a set of 15 PBND-resistant peanut genotypes. Nipaporn et al. (2008) for the first time identified a RAPD marker OPG16850 linked to PBND resistance in peanut.

In the present study, the genetic map with 191 markers distributed on 22 linkage groups (Ravi et al., 2011) was used to identify QTL associated with PBND resistance using composite interval mapping (CIM; Zeng, 1994). A total of five QTL on LG_AhIX, LG_Ahll, and LG_AhVIII with PVE ranging from $3.92 \%$ to $12.57 \%$ were identified for per cent disease incidence at 30,60 and 90 DAS. To minimize the possibility of identifying false positive and false negative QTL for the thresholds, two softwares, namely QTL Cartographer and QTLNetwork were employed to identify main effect QTL (M-QTL). M-QTL for PBND parameter (q60DI_2014) were positioned on the same linkage group (i.e., LG_AhIl) using both softwares. Another major QTL viz., q90DI_2015 (LOD 3.06) located on LG_AhVIII was identified using Cartographer with high PVE of about $12.57 \%$. However, none of the detected M-QTL could be identified in both the sowing seasons, indicating the need for further confirmation/ validation prior to their application in crop improvement. No QTL were identified for per cent of PBND incidence at 30 and 90 DAS, days to $50 \%$ flowering, pod yield per plot, shelling percent, 100 seed weight and haulm yield per plot through QTL Network.

In contrast, QTL Cartographer identified M-QTL for per cent of PBND incidence at 30 and 90 DAS, days to $50 \%$ flowering (qD50F_2015) on LG XVIII with PVE of 4.91 and LOD 2.76, pod yield per plot (qPYP_2014) on LG V and XV with PVE of 4.79 and 5.92 and LOD 3.92 and 3.13, respectively, haulm yield per plot (qHYP_2015) on LG VIII with PVE of 4.24 and LOD 3.07, 100 seed weight (qHSW_2014; qHSW_2015) on LG XVII and XIII with PVE of 8.24 and 11.18 and LOD 3.33 and 3.17 respectively. For pod yield per plot, PBND incidence at 30 DAS and days to maturity QTL Cartographer identified more than one quantitative trait locus with less PVE. Due to the low PVE values and non-detection across seasons, further validation of these QTL by using third season data or by developing a new population would be useful.

The studies on QTL identification in other crop species including peanut have reported that quantitative variation is either governed by a few QTL with large effect or large number of genes having progressively small effect. As multiple, small effect QTL govern the PBND resistance traits in the study, we conducted E-QTL analysis to understand epistatic effects by QTL Network which revealed significant AA effect. No AAE effects were detected. No epistatic interactions involving a main effect QTL were detected and most of the detected AA effects came from small effect QTL. As the trait 60DI showed significant additive effects and AA epistatic effects with high PVE values and the additive allele contribution coming from the parent it can be exploited in PBND resistance breeding programme.

In the present study, several M-QTL could be identified for PBND at 30, 60 and 90 DAS during 2014 and 2015 rainy season (Table 4). However, no common QTL could be observed and most of the detected QTL had low PVE. The absence of consistent QTL in the evaluating years can be explained by the quantitative nature of PBND trait being governed by several small effect QTL/genes present in different chromosomal regions. The quantitative nature of PBND in peanut has been studied earlier and reported by Buiel (1996), Kesmala (2003), Pensuk, Wongkaew, et al. (2002), Pensuk et al. (2004) and Poledate et al. (2007). The low PVE values observed in the study could be due to a number of factors that can influence the rate of disease incidence such as the resistance level of the host genotype, the conduciveness of the environment for homogeneous distribution of the infection, per cent of PBND incidence, and influence of agronomic and other yield traits. One M-QTL with a high PVE of $12.57 \%$ was observed during rainy season 2015 . This can be exploited in PBND resistance breeding programmes after further validations. QTL with phenotypic variance of $6.63 \%-15.6 \%$ for leaf spot and tomato spotted wilt virus diseases resistance in peanut were used for marker development (Pandey et al., 2017). However, M-QTL did not explain high phenotypic variance for yield and its contributing traits in both the seasons of the majority identified.

This is the first report to be presented with identification of QTL associated with resistance to PBND in a mapping population comprising of 318 RILs. Therefore, PBND resistance in peanut is governed by more number of $\mathrm{M}-\mathrm{QTL}$ each with a small phenotypic effect. Integration of all these M-QTL to an elite cultivar might not be possible due to extensive segregation in early generations. However, through intercrossing of selected RILs using MAB, it is possible to integrate most of these M-QTL into a single progeny which can then be utilized in crop improvement. To identify QTL with high PVE, more efforts need to be directed to increase the population size or target different seasons/multiple locations or both. This will help to improve upon linkage disequilibrium resulting in higher PVE. Also, the use of multi-season/location trial will help to understand the effects of environment on the genotype for PBND reaction better.

In summary, the study reports the construction of a QTL map by using an available framework linkage map on 318 RIL mapping 
population of cross TAG $24 \times$ ICGV 86031 and identification of QTL for PBND and yield parameters on 22LGs. This map can be utilized to identify potential linked markers for PBND resistance in peanut. The QTL identified in the study need to be further validated through increasing the population size or through multi-season/location evaluations to improve upon the PVE values and identify linked markers that can be used in MAB. Superior performing RILs identified in the study can be recycled into the breeding programme or released as variety following further evaluations.

\section{ACKNOWLEDGEMENTS}

The financial assistance for research work and fellowship to first author were supported by OPEC Fund for International Development (OFID), and Bill and Melinda Gates Foundation (BMGF) supported project on Tropical Legumes (TL) II program. The work has been undertaken as part of $\mathrm{PhD}$ research at ICRISAT under CGIAR Research Program on Grain legumes and Dryland Cereals (CRP-GLDC).

\section{CONFLICT OF INTEREST}

The authors declare that the research was conducted in the absence of any personal, professional or financial relationships that could potentially be constructed as a conflict of interest.

\section{AUTHOR CONTRIBUTION}

PJ, Y and KPV: Conceived and designed the experiment; Y, SM and GS: Conducted the experiment and recorded the observations; Y, YS and MTV: Analysed data; Y, PJ, MTV, MKP, PK and YS: Interpreted results; PJ, MTV, SM, SN, GS and Y: Population developed and phenotyping. Y, MTV, PJ, MPK, PK and RKV: Wrote and edited the manuscript.

\section{ORCID}

Rajeev K. Varshney (iD https://orcid.org/0000-0002-4562-9131 Janila Pasupuleti (iD https://orcid.org/0000-0003-2583-9630

\section{REFERENCES}

Basu, M. S. (1995). Peanut bud necrosis disease: Activities in the Indian national program. In A. M. Buiel, J. E. Parlevliet \& J. M. Lenne (Eds.), Recent studies on peanut bud necrosis disease (pp. 61-63). Patancheru, India: ICRISAT Asia Center.

Bera, S. K., Kamdar, J. H., Maurya, A. K., \& Dash, P. (2014). Molecular diversity and association of simple sequence repeat markers with bud necrosis disease in interspecific breeding lines and cultivars of peanut (Arachis hypogaea L.). Australian Journal of Crop Sciences, 8(5), 771-780.

Bertioli, D. J., Cannon, S. B., Froenicke, L., Huang, G., Farmer, A. D., Cannon, E. K., ... Ozias-Akins, P. (2016). The genome sequences of Arachisduranensis and Arachisipaensis, the diploid ancestors of cultivated peanut. Nature Genetics, 48, 438-446. https://doi. org/10.1038/ng.3517
Bhatnagar, H., Reddy, M. V., Rao, J. N., \& Singh, P. (1995). Confirmation of the effects of plant density and irrigation on peanut bud necrosis incidence. International Arachis Newsletter, 15, 52-53.

Buiel, A. A. M. (1996). Quantitative resistance to peanut bud necrosis tospovirus in groundnut. PhD Thesis. Wageningen Agricultural University, The Netherlands.

Buiel, A. A. M., Lenne, P. J. E., \& Jillian, M. (1995). Recent studies on peanut bud necrosis disease. Proceedings of a Meeting 20 Mar 1995.

Chen, X., Li, H., Pandey, M. K., Yang, Q., Wang, X., Garg, V., ... Yu, S. (2016). Draft genome of the peanut A-genome progenitor (Arachis duranensis) provides insights into geocarpy, oil biosynthesis, and allergens. Proceedings of the National Academy of Sciences of the United States of America, 113, 6785-6790. https://doi.org/10.1073/ pnas.1600899113

Chu, Y., Wu, C. L., Holbrook, C. C., Tillman, B. L., Person, G., \& OziasAkins, P. (2011). Marker-assisted selection to pyramid nematode resistance and the high oleic trait in peanut. Plant Genome, 4, 110-117. https://doi.org/10.3835/plantgenome2011.01.0001

Dwivedi, S. L., Nigam, S. N., Reddy, D. V. R., Reddy, A. S., \& Ranga Rao, G. V. (1995). Progress in breeding groundnut varieties resistant to peanut bud necrosis virus and its vector. In A. A. M. Buiel, J. E. Parlevliet $\&$ J. M. Lenne (Eds.), Recent studies on peanut bud necrosis disease (pp. 35-40). Proceedings of a Meeting. Patancheru, India: ICRISAT.

Dwivedi, S. L., Reddy, D. V. R., Nigam, S. N., Ranga Rao, G. V., Wightman, J. A., Amin, P. W., ... Ramraj, V. M. (1993). Registration of ICGV 86031 peanut germplasm. Crop Sciences, 33, 220.

FAO (2014). Statistical database. Rome, Italy: FAO.

Gopal, K., \& Upadhyaya, H. D. (1991). Effect of bud necrosis disease on the yield of groundnut under field condition. Indian Phytopathology, 44, 221-223.

Grafius, J. E. (1959). Heterosis in barley. Agronomy Journal, 51, 551-554.

Holbrook, C. C., Ozias-Akins, P., Chu, Y., \& Guo, B. (2011). Impact of molecular genetic research on peanut. Agronomy, 1, 3-17.

Janila, P., Pandey, M. K., Manohar, S., Variath, M., Nallathambi, P., Nadaf, H. L., ... Varshney, R. K. (2015). Foliar fungal disease-resistant introgression lines of groundnut (Arachis hypogaea L.) record higher pod and haulm yield in multi location testing. Plant Breeding, 135(3), 355-366.

Janila, P., Pandey, M. K., Shasidhar, Y., Variath, M. T., Sriswathi, M., Khera, P., ... Varshney, R. K. (2016). Molecular breeding for introgression of fatty acid desaturase mutant alleles (ahFAD2A and ahFAD2B) enhances oil quality in high and low oil containing peanut genotypes. Plant Sciences, 242, 203-213. https://doi.org/10.1016/j.plant sci.2015.08.013

Janila, P., Ramaiah, V., Rathore, A., Upakula, A., Reddy, R. K., Waliyar, F., \& Nigam, S. N. (2013). Genetic analysis of resistance to late leaf spot in interspecific groundnuts. Euphytica, 193, 13-25. https://doi. org/10.1007/s10681-013-0881-7

Johanson, H. W., Robinson, H. F., \& Comstock, R. E. (1955). Estimation of genetic variability and environmental variability in soybean. Agronomy Journal, 47, 314-318.

Kamdar, J. H., Goswami, B. R., \& Bera, S. K. (2014). Genetic molecular diversity in interspecific peanut lines differing in temporal resistance to peanut bud necrosis disease. African Journal of Biotechnology, 13(3), 385.

Kesmala, T. (2003). Inheritance of resistance to peanut bud necrosis disease and agronomic traits in large-seeded type peanut. M.S. Thesis, Khon Kaen University, Thailand (in Thai with English summary).

Kesmala, T., Jogloy, S., Wongkaew, S., Akkasaeng, C., Vorasoot, N., \& Patanothai, A. (2004). Heritability and phenotypic correlation of resistance to peanut bud necrosis virus (PBNV) and agronomic traits in peanut. Songklanakarin Journal of Science and Technology, 26(2), 129-138.

Khote, A. C., Patil, P. P., Patil, S. P., \& Walke, B. K. (2009). Genetic variability studies in groundnut (Arachis hypogaea L.). International Journal of Plant Sciences, 4(1), 141-149. 
Naidu, R. A., Kimmins, F. M., Deom, C. M., Subrahmayam, P., Chiyembekeza, A. J., \& vander Merwe, P. J. A. (1999). Groundnut rosette: A virus disease affecting groundnut production in sub-saharan Africa. Plant Disease, 83(8), 700-712.

Nath, U. K., \& Alam, M. S. (2002). Genetic variability, heritability and genetic advance of yield and related traits of groundnut (Arachis hypogaea L.). Online Journal of Biological Sciences, 2(11), 762-764. https:// doi.org/10.3923/jbs.2002.762.764

Nigam, S. N. (2015). Groundnut at a glance. U.S Governments feed the future innovation lab for collaborative research in peanut productivity and mycotoxin control. pp. 57-58.

Nipaporn, S., Pensuk, V., Jogloy, S., \& Sanitchon, J. (2008). Bulked segregant analysis for identifying RAPD marker linked to bud necrosis disease resistance in peanut. Khon Kaen Agriculture Journal, 36, 48-55.

Palmer, J. M., Reddy, D. V. R., Wightman, J. A., \& Ranga Rao, G. V. (1990). New information on the thrips vectors of tomato spotted wilt virus in groundnut crops in India. International Arachis Newsletter, 7, 24-25.

Pandey, M. K., Wang, H., Khera, P., Vishwakarma, M. K., Kale, S. M., Culbreath, A. K., ... Guo, B. (2017). Genetic dissection of novel QTLs for resistance to leaf spots and tomato spotted wilt virus in peanut (Arachis hypogaea L.). Frontiers in Plant Sciences, 8, 25. https://doi. org/10.3389/fpls.2017.00025

Parameshwarappa, K. G., Shobha Krupa Rani, K., \& Bentur, M. G. (2005). Genetic variability and character association in large seeded groundnut genotypes. Karnataka Journal of Agriculture Science, 18(2), 329-333.

Patil, S., Shivanna, S., Irappa, B. M., \& Shweta, P. (2015). Genetic variability and character association studies for yield and yield attributing components in groundnut (Arachis hypogeae L.). International Journal of Recent Scientific Research, 6(6), 4568-4570.

Pensuk, V., Daengpluang, N., Wongkaew, S., Jogloy, S., \& Patanothai, A. (2002). Evaluation of screening procedures to identify peanut resistance to peanut bud necrosis virus (PBNV). Peanut Science, 29(1), 47-51. https://doi.org/10.3146/pnut.29.1.0009

Pensuk, V., Jogloy, S., \& Patanothai, A. (2010). Effects of temperature and relative humidity on the effectiveness of peanut bud necrosis virus inoculation in peanut. Plant Pathology Journal, 9, 188-193.

Pensuk, V., Jogloy, S., Wongkaew, S., \& Patanothai, A. (2004). Generation means analysis of resistance to peanut bud necrosis caused by peanut bud necrosis tospovirus in peanut. Plant Breeding, 123, 90-92. https://doi.org/10.1046/j.0179-9541.2003.00928.x

Pensuk, V., Wongkaew, S., Jogloy, S., \& Patanothai, A. (2002). Combining ability for resistance in peanut (Arachis hypogaea L.) to peanut bud necrosis tospovirus (PBNV). Annals of Applied Biology, 141(2), 143-146.

Poledate, A., Laohasiriwong, S., Jaisil, P., Vorasoot, N., Jogloy, S., Kesmala, T., \& Patanothai, A. (2007). Gene effects for parameters of peanut bud necrosis virus (PBNV). Pakistan Journal of Biological Sciences, 10(9), 1501-1506.

Puttha, R., Jogloy, S., Wongkaew, S., Sanitchon, J., Kesmala, T., \& Patanothai, A. (2008). Heritability, phenotypic and genotypic correlation of peanut bud necrosis virus resistance and agronomic traits in peanut. Asian Journal of Plant Sciences, 7(3), 276-283. https://doi. org/10.3923/ajps.2008.276.283

Qin, H., Feng, S., Chen, C., Guo, Y., Knapp, S., Culbreath, A., ... Guo, B. (2012). An integrated genetic linkage map of cultivated peanut (Arachis hypogaea L.) constructed from two RIL populations. Theoretical and Applied Genetics, 124(4), 653-664.

Ravi, K., Vadez, V., Isobe, S., Mir, R. R., Guo, Y., Nigam, S. N., ... Varshney, R. K. (2011). Identification of several small main-effect QTLs and a large number of epistatic QTLs for drought tolerance related traits in groundnut (Arachis hypogaea L.). Theoretical and Applied Genetics, 122, 1119-1132. https://doi.org/10.1007/s00122-010-1517-0

Reddy, A. S., Reddy, L. J., Mallikarjuna, N., Abdurahman, M. D., Reddy, Y. V., Bramel, P. J., \& Reddy, D. V. R. (2000). Identification of resistance to Peanut bud necrosis virus (PBNV) in wild Arachis germplasm. Annals of Applied Biology, 137, 135-139.

Reddy, D. V. R., Buiel, A. A. M., Satyanarayana, T., Dwivedi, S. L., Reddy, A. S., Ratna, A. S., ... Wightman, J. A. (1995). Peanut bud necrosis disease: An overview. In A. A. M. Buiel, J. E. Parlevliet \& J. M. Lenne (Eds.), Recent studies on peanut bud necrosis disease: Proceedings of a Meeting (pp. 3-7). Patancheru, India: ICRISAT Asia Center.

Satyanarayana, T., Mitchell, S. E., Reddy, D. V. R., Brown, S., Kresovich, S., Jarret, R., ... Demski, J. W. (1996). Peanut bud necrosis tospovirus $S$ RNA: Complete nucleotide sequence, genome organization and homology to other tospoviruses. Archives of Virology, 141, 85-98. https ://doi.org/10.1007/BF01718590

Shaner, G., \& Finney, R. E. (1977). The effect of nitrogen fertilization on expression of slow-mildewing resistance in Knox wheat. Phytopathology, 67, 1051-1056.

Singh, B. R., Gupta, S. P., \& Kaushik, D. C. (1997). Incidence and losses due to bud necrosis and peanut mottle diseases. Indian Journal of Virology, 13, 45-46.

Srinivasaraghavan, A., Sunkad, G., Bera, S. K., \& Revadi, M. (2012). Molecular diversity analysis in peanut bud necrosis disease resistant peanut genotypes. Bioinfolet, 9(4), 622-626.

Tabassum, A., Bhat, N. B., \& Sudini, H. (2017). Reaction of groundnut advanced lines to groundnut bus necrosis disease. International Journal of Current Microbiology and Applied Sciences, 6(10), 1790-1802.

Tonsomors, Y., Jogloy, S., Wongkew, S., Akkasaeng, C., Kesmala, T., \& Patanothai, A. (2006). Heritability, phenotypic and genotypic correlations of peanut bud necrosis virus (PBNV) reaction parameters in peanut. Songklanakarin Journal of Science and Technology, 28, 469-477.

Ungerer, M. C., Halldorsdottir, S. S., Modliszewski, J. L., Mackay, T. F. C., \& Purugganan, M. D. (2002). Quantitative trait loci for inflorescence development in Arabidopsis thaliana. Genetics, 160, 1133-1151.

Varshney, R. K., Bertioli, D. J., Moretzsohn, M. C., Vadez, V., Krishnamurthy, L., Aruna, R., ... Hoisington, D. A. (2009). The first SSR based genetic linkage map for cultivated groundnut (Arachis hypogaea L.). Theoretical and Applied Genetics, 118, 729-739. https:// doi.org/10.1007/s00122-008-0933-x

Varshney, R. K., Pandey, M. K., Janila, P., Nigam, S. N., Sudini, H., Gowda, M. V. C., ... Nagesh, P. (2014). Marker-assisted introgression of a QTL region to improve rust resistance in three elite and popular varieties of peanut (Arachis hypogaea L.). Theoretical and Applied Genetics, 127, 1771-1781. https://doi.org/10.1007/s00122-014-2338-3

Vekariya, H. B., Khanpara, M. D., Vachhani, J. H., Kachhadia, V. H., Madariya, R. B., \& Jivani, L. L. (2011). Variability and heritability studies in bunch groundnut (Arachis hypogaea L.). International Journal of Agricultural Sciences, 7(1), 32-34.

Vijaya Lakshmi, K., Wightman, J. A., Reddy, D. V. R., Ranga Rao, G. V., Buiel, A. A. M., \& Reddy, D. D. R. (1995). Transmission of peanut bud necrosis virus by Thrips palmi in India. In B. L. Parker, M. Skinner \& T. Lewis (Eds.), Thrips biology and management (Vol. 276, pp. 179-184). NATO ASI Series, Life Sciences. New York, NY and London, UK: Plenum Press.

Vishnuvardhan, K. M., Vasanthi, R. P., \& Hariprasad Reddy, K. (2012). Genetic variability studies for yield, yield attributes and resistance to foliar diseases in Groundnut (Arachis hypogaea L.). Legume Research, 36(2), 111-115.

Voorrips, R. E. (2002). MapChart: Software for the graphical presentation of linkage maps and QTLs. The Journal of Heredity, 93, 77-78. https://doi.org/10.1093/jhered/93.1.77

Wang, S., Basten, C. J., \& Zeng, Z. B. (2007). Windows QTL cartographer 2.5. Retrieved from http://statgen.ncsu.edu/qtlcart/WQTLCart.html

Wongkaew, S. (1993). Peanut virus diseases in Thailand. Oil Seed Crops and Food Legume Sub Div., Rice and Field Crops Promotion Div., 
Dept. of Agric. Ext., Ministry of Agric. And Coop., Bangkok, Thailand (In Thai).

Yang, J., Hu, C. C., Ye, X. Z., \& Zhu, J. (2005). QTLNetwork 2.0. Institute of Bioinformatics, Zhejiang University, Hangzhou, China. Retrieved from http://ibi.zju.edu.cn/software/qtInetwork

Zaman, M. A., Tuhina-Khatun, M., Ullah, M. Z., Moniruzzamn, M., \& Alam, K. H. (2011). Genetic variability and path analysis of groundnut (Arachis hypogaea L.). The Agriculturists, 9(1-2), 29-36.

Zeng, Z. B. (1994). Precision mapping of quantitative trait loci. Genetics, 136, 1457-1468.

Zhou, X., Xia, Y., Ren, X., Chen, Y., Huang, L., Huang, S., ... Jiang, H. S. (2014). Construction of an SNP-based genetic linkage map in cultivated peanut based on large scale marker development using next-generation double-digest restriction-site-associated DNA sequencing (ddRADseq). BMC Genomics, 15, 351.

How to cite this article: Jadhav Y, Manohar SS, Sunkad G, et al. Genomic regions associated with resistance to peanut bud necrosis disease (PBND) in a recombinant inbred line (RIL) population. Plant Breed. 2019;00:1-13. https://doi. org/10.1111/pbr.12743 